\title{
Weight management merits attention in women with infertility: a cross-sectional study on the association of anthropometric indices with hormonal imbalance in a Ghanaian population
}

William K. B. A. Owiredu', Peter Ntim Ofori ${ }^{2}$, Cornelius Archer Turpin ${ }^{3}$, Christian Obirikorang ${ }^{1}$, Emmanuel Acheampong ${ }^{4}$, Enoch Odame Anto ${ }^{4}$, Eddie-Williams Owiredu ${ }^{1}$ and Evans Asamoah Adu ${ }^{1 *}$ (i)

\begin{abstract}
Objective: This study determined the association of anthropometric indices with hormonal imbalance among infertile women in a Ghanaian population.

Results: Follicle stimulating hormone (FSH) levels (18.47 vs. 8.67, p-value $=0.002)$, and luteinizing hormone (LH) $(12.43$ vs. 8.01, $\mathrm{p}$-value $=0.044)$ were higher in women with primary infertility compared with women presenting with secondary infertility. Waist circumference (WC) and waist-to-height ratio (WHtR) showed significant negative partial correlation with prolactin in both primary and secondary infertile women. Also a significant negative partial correlation was observed between BMI and prolactin in secondary infertile women only. Waist-to-hip ratio (WHR) showed a positive association with LH in both primary and secondary infertility. WHR also showed significant positive correlation to LH/FSH ratio in secondary infertility whereas body adiposity index (BAl) showed a negative correlation to LH/ FSH ratio. In a correlation analysis of anthropometric measures with hormonal profile and causes of infertility as a fixed factor, the association between anthropometric indices and fertility hormones was largely dependent on the underlying causes of infertility.
\end{abstract}

Keywords: Anthropometric indices, Fertility hormones, Hormonal imbalance

\section{Introduction}

Infertility is a recognised public health issue, which is associated with medical, psychosocial and economics burden according to the World Health Organization (WHO) $[1,2]$. It is a problem of global shares, affecting an average of $8 \%$ to $12 \%$ of couples worldwide [2]. Countries within the Sub-Saharan Africa (SSA), southern and central part of Africa, records as high as $30.0 \%$ prevalence of infertility among couples [3-5]. In Ghana, the

\footnotetext{
*Correspondence: evansasamoahadu@gmail.com

${ }^{1}$ Department of Molecular Medicine, School of Medicine and Dentistry, Kwame Nkrumah University of Science and Technology, Kumasi, Ghana Full list of author information is available at the end of the article
}

prevalence rate of infertility is reportedly $11.8 \%$ among women and $15.8 \%$ among men [6].

Overweight/obesity influences fertility by affecting ovulatory function [7]. Chang [8] indicated that the complex hormonal balance of the hypothalamic-pituitary-gonadal axis is affected by an individual's body mass index (BMI). Thus, the interplay between fertility and obesity is the effect of obesity on menstrual disturbances and subfertility, although the exact mechanism has not been clearly elucidated $[9,10]$. Pandey et al. [9] reported that overweight and obese women have poorer outcomes following fertility treatment. Thus, highlighting the significant effect of extreme weight on fertility especially among women. 
Functional redundancy of the gonadotropin releasing hormone $(\mathrm{GnRH})$ causes disruption of the normal secretion of luteinizing hormone $(\mathrm{LH})$ and follicle stimulating hormone (FSH), which is involved in a number of reproductive disorders in women $[11,12]$. Measurements of hormones including prolactin and thyroid stimulating hormones has a diagnostic value in the evaluation of women fertility function [13]. Seth et al. [10] in recent years reported an association between obesity indices and hormonal derangements among infertile women. Prolactin (PRL) levels, which is significant in evaluating female fertility, may be secreted from adipose tissues [14]. Thus, providing a link between obesity and hyperprolactinemia. In Ghana, studies evaluating the effect of weight-related behaviours on fertility hormones are lacking. Therefore, this study evaluated the association of anthropometric indices with hormonal imbalance among infertile women in a Ghanaian population.

\section{Main text \\ Methods}

The study was a cross-sectional study conducted at the Department of Obstetrics and Gynaecology at the Komfo Anokye Teaching Hospital. All patients visiting the department for infertility issues and above 18 years from September 2015, to March 2018 were included as a sample. Those who were psychologically, physically and socially fit after an investigation by a gynaecologist were selected to partake in the study. Women with infectious conditions such as human immunodeficiency virus (HIV), Hepatitis B and C, and Tuberculosis were excluded from the study. Patients on any kind of hormone treatment or those with LH and FSH levels suggestive of menopausal state were excluded from the study. In total, 184 infertile women were included.

A brief consultation was conducted and appointment made with participants based on knowledge of their last menstrual periods for blood samples to be taken for 21-day progesterone $(\mathrm{ng} / \mathrm{ml}), \mathrm{LH}(\mathrm{mIU} / \mathrm{ml}), \mathrm{FSH}(\mathrm{mIU} /$ $\mathrm{ml})$ and PRL (ng/ml) levels. Participants were asked to complete a structured questionnaire which asked about age, and years of infertility. Causes of infertility were extracted from the patient's folder. Weight $(\mathrm{kg})$ of each participant was measured using a platform electronic scale. Waist and hip circumference were measured using non-extensible tape measure at the point of the umbilicus and the maximal gluteal position, respectively. A stadiometer was used for body height in a good standing posture. BMI was calculated as an index of body weight and height $\left(\mathrm{kg} / \mathrm{m}^{2}\right)$. WHR and WHtR were estimated from the ratio of waist $(\mathrm{cm})$ to hip $(\mathrm{cm})$ and waist $(\mathrm{cm})$ to height $(\mathrm{cm})$, respectively. Abdominal volume index (AVI) and BAI were calculated using the formulae by
[15] and [16], respectively. Two millilitres fasting venous blood sample was drawn from the subject on the twentyfirst day of menstrual cycle using standard venepuncture techniques into plain vacutainers without any additive. Serum separated after clotting was used for the estimation of fertility hormones using mini VIDAS $^{\circledR}$ Hormonal Analyser (BioMerieux ${ }^{\circledR}$ SA, France).

Statistical analysis was done using Statistical package for Social Sciences (SPSS) version 25 for windows. Kolmogorov-Smirnov test was used to assess the normality of the data. Partial Pearson's correlation analysis adjusted for age and duration of infertility were used to determining the correlation between anthropometric indices and hormonal factors. p-value $<0.05$ was considered as statistically significant.

\section{Results}

Women with secondary infertility were older compared with women with primary infertility (34.9 vs. 30.3 years, p-value $<0.0001)$. A higher proportions of women with primary infertility were young adults (79.6\%) whereas a higher percentage of women with secondary infertility were middle aged adults (51.3\%). Mean FSH (18.47 vs. 8.67, p-value $=0.002$ ), and LH (12.43 vs. 8.01, $\mathrm{p}$-value $=0.044$ ) were higher for women with primary infertility compared with secondary infertility, respectively (Table 1).

A significant negative partial correlation was observed between BMI and prolactin in secondary fertility $(\mathrm{R}=-0.24, \mathrm{p}$-value $=0.036) . \mathrm{WC}$ had a negative association with prolactin in both primary $(R=-0.236)$ and secondary $(R=-0.232)$ infertility. WHtR had a significant negative partial correlation with prolactin in both primary $(R=-0.226)$ and secondary $(R=-0.256)$ infertility. WHR correlated positively with LH in both primary $(R=0.213)$ and secondary $(R=0.229)$ infertility. Also WHR showed significant positive partial correlation to $\mathrm{LH} / \mathrm{FSH}$ ratio in secondary infertility $(\mathrm{R}=0.299)$. BAI showed a negative partial correlation to $\mathrm{LH} / \mathrm{FSH}$ ratio $(\mathrm{R}=-0.263)$ (Table 2).

WC $(R=0.45)$ and WHtR $(R=0.38)$ had a significant partial positive correlation to $\mathrm{LH}$ among patients with polycystic ovarian syndrome (PCOS) as the cause of infertility. WC and WHtR had a significantly partial correlation to FSH ( $R=0.64$ and 0.58 , respectively) among patients with hyperprolactinemia as the cause of infertility. Among patients with tubal cause of infertility, a significant partial negative correlation was observed between WC $(R=-0.53)$, WHtR $(R=-0.55)$, WHR $(R=-0.41)$, BAI $(R=-0.44)$ and prolactin. Also significant partial negative association was observed for WC, WHtR and BAI to FSH $(\mathrm{R}=-0.35,-0.33$ and -0.35 , respectively) among patients with tubal causes of infertility. Moreover, 
Table 1 Basic characteristics of the study participants

\begin{tabular}{|c|c|c|c|}
\hline Variable & $\begin{array}{l}\text { Primary infertility } \\
(n=108)\end{array}$ & $\begin{array}{l}\text { Secondary infertility } \\
(n=76)\end{array}$ & p-value \\
\hline Duration of infertility ${ }^{\mathrm{a}}$ & $4.0 \pm 0.39$ & $5.5 \pm 0.42$ & $<0.0001$ \\
\hline Age (years) ${ }^{\mathrm{a}}$ & $30.3 \pm 0.56$ & $34.9 \pm 0.61$ & $<0.0001$ \\
\hline \multicolumn{4}{|l|}{ Age staging } \\
\hline Young adults (19-34 years) & $86(79.6)$ & $37(48.7)$ & $<0.0001$ \\
\hline Middle-aged adults ( $\geq 35$ years) & $22(20.4)$ & $39(51.3)$ & $<0.0001$ \\
\hline \multicolumn{4}{|l|}{ Aetiology } \\
\hline Hyperprolactinemia & $17(15.7)$ & $6(7.9)$ & 0.113 \\
\hline Tubal factors & $30(27.8)$ & $8(10.5)$ & 0.004 \\
\hline Male factors & $18(16.7)$ & $6(7.9)$ & 0.082 \\
\hline Ovulation problems & $3(2.8)$ & $20(26.3)$ & $<0.0001$ \\
\hline PCOS & $16(14.8)$ & $15(19.7)$ & 0.380 \\
\hline Endometriosis & $2(1.9)$ & $4(5.3)$ & 0.200 \\
\hline Uterine causes & $14(13.0)$ & $14(18.4)$ & 0.310 \\
\hline Unexplained causes & $14(13.0)$ & $11(14.5)$ & 0.769 \\
\hline Body mass index $\left(\mathrm{kg} / \mathrm{m}^{2}\right)^{\mathrm{a}}$ & $28.6 \pm 0.50$ & $29.8 \pm 0.54$ & 0.116 \\
\hline Waist circumference $(\mathrm{cm})^{\mathrm{a}}$ & $88.6 \pm 1.07$ & $88.2 \pm 1.07$ & 0.832 \\
\hline Waist-to-hip ratio ${ }^{a}$ & $0.87 \pm 0.01$ & $0.86 \pm 0.01$ & 0.088 \\
\hline Waist-to-height ratio ${ }^{a}$ & $0.56 \pm 0.01$ & $0.55 \pm 0.01$ & 0.408 \\
\hline Body adiposity index ${ }^{a}$ & $32.3 \pm 0.50$ & $32.5 \pm 0.64$ & 0.816 \\
\hline Progesterone $(\mathrm{ng} / \mathrm{ml})^{\mathrm{a}}$ & $8.94 \pm 0.58$ & $7.52 \pm 0.58$ & 0.547 \\
\hline $\mathrm{FSH}(\mathrm{mlU} / \mathrm{ml})^{\mathrm{a}}$ & $18.47 \pm 2.18$ & $8.67 \pm 1.17$ & 0.002 \\
\hline $\mathrm{LH}(\mathrm{mlU} / \mathrm{ml})^{\mathrm{a}}$ & $12.43 \pm 1.25$ & $8.01 \pm 0.97$ & 0.044 \\
\hline LH/FSH ratio ${ }^{a}$ & $1.00 \pm 0.10$ & $1.28 \pm 0.18$ & 0.061 \\
\hline Prolactin $(\mathrm{ng} / \mathrm{ml})^{\mathrm{a}}$ & $20.41 \pm 1.93$ & $17.99 \pm 1.58$ & 0.060 \\
\hline
\end{tabular}

All values are presented as frequency and column proportions, unless otherwise specified. Highlighted values are statistically significant Values highlighted in italics are statistically significant

PCOS polycystic ovarian syndrome, FSH follicle stimulating hormone, LH luteinizing hormone

a Denotes values presented as mean \pm standard error of mean

among patients with tubal causes of infertility, WHR was positively correlated to progesterone $(\mathrm{R}=0.40)$, whereas WHtR showed positive correlation to $\mathrm{LH} / \mathrm{FSH}(\mathrm{R}=0.34)$. Among patents with male partner being the cause of infertility, BMI, WC, WHR and WHtR showed significant negative partial correlation to progesterone. Moreover, BMI showed negative partial correlation to LH/FSH ratio $(\mathrm{R}=-0.53)$. Among patients with unexplained causes of infertility, WC, WHtR and WHR showed a significant partial correlation to prolactin (Table 3).

\section{Discussion}

Our findings indicates that women with secondary infertility were older and had longer duration of infertility compared with those with primary infertility. This finding is consistent with the findings of Seth et al. [10] and highlights the independent role of age in fertility function of women [17]. This age phenomenon suggests decreased fecundity in secondary infertile women who have been successful in having their previous pregnancies. Ages beyond 32-years reflects decrease in egg quality in association with a gradual increase in circulating level of FSH, declines in circulating anti-müllerian hormone and inhibin B concentrations [18].

One important finding of this study was that fertility hormones including FSH and LH were higher and above normal range in women with primary infertility compared with secondary infertility. Additionally, although not significant, levels of progesterone and PRL were high in women with primary infertility compared with secondary infertility. This finding aligns the findings of AlTurki [19]. Generally, FSH stimulates several follicles to mature and LH kindles ovulation by causing the dominant follicle to burst and release its eggs into the fallopian tube. High LH and FSH levels increase ovarian testosterone production, alter oestrogen production, and causes abnormalities with ovulation. The levels of LH and FSH, observed among primary infertile women is suggestive of a possible primary ovarian failure and poor pregnancy outcomes $[18,20]$. 
Table 2 Partial correlation of anthropometric measures with hormonal profile in primary and secondary fertility

\begin{tabular}{|c|c|c|c|c|c|c|c|c|c|c|}
\hline \multirow[t]{2}{*}{ Variable } & \multicolumn{5}{|c|}{ Primary infertility } & \multicolumn{5}{|c|}{ Secondary infertility } \\
\hline & PRG & FSH & LH & PRL & Ratio & PRG & FSH & LH & PRL & LH/FSH \\
\hline \multicolumn{11}{|l|}{ BMI } \\
\hline $\mathrm{R}$ & 0.029 & -0.028 & 0.025 & -0.09 & 0.046 & 0.09 & 0.123 & 0.204 & -0.24 & 0.218 \\
\hline$p$-value & 0.762 & 0.773 & 0.794 & 0.353 & 0.638 & 0.439 & 0.291 & 0.077 & 0.036 & 0.058 \\
\hline \multicolumn{11}{|l|}{ WC } \\
\hline $\mathrm{R}$ & 0.061 & 0.03 & 0.178 & -0.236 & 0.085 & 0.169 & -0.039 & 0.013 & -0.232 & 0 \\
\hline$p$-value & 0.531 & 0.756 & 0.065 & 0.014 & 0.382 & 0.145 & 0.741 & 0.913 & 0.044 & 0.999 \\
\hline \multicolumn{11}{|l|}{ WHR } \\
\hline $\mathrm{R}$ & 0.118 & 0.049 & 0.213 & -0.098 & 0.149 & 0.089 & -0.062 & 0.229 & -0.151 & 0.299 \\
\hline$p$-value & 0.222 & 0.616 & 0.027 & 0.311 & 0.124 & 0.443 & 0.594 & 0.047 & 0.192 & 0.009 \\
\hline \multicolumn{11}{|l|}{ WHtR } \\
\hline $\mathrm{R}$ & 0.027 & -0.021 & 0.116 & -0.226 & 0.057 & 0.179 & 0.011 & -0.024 & -0.256 & -0.103 \\
\hline$p$-value & 0.783 & 0.832 & 0.232 & 0.019 & 0.56 & 0.122 & 0.924 & 0.838 & 0.025 & 0.377 \\
\hline \multicolumn{11}{|l|}{$\mathrm{BAI}$} \\
\hline$R$ & -0.092 & -0.11 & -0.091 & -0.183 & -0.08 & 0.135 & 0.097 & -0.116 & -0.21 & -0.263 \\
\hline$p$-value & 0.342 & 0.258 & 0.351 & 0.058 & 0.408 & 0.244 & 0.405 & 0.317 & 0.068 & 0.022 \\
\hline
\end{tabular}

Values highlighted in italics are statistically significant

$R$ partial correlation coefficient (adjusted for age and duration of condition), BMI body mass index, WC waist circumference, $W H R$ waist-to-hip ratio, $W H t R$ waist-toheight ratio, BAl body adiposity index, PRG progesterone, FSH follicle stimulating hormone, $L H$ luteinizing hormone, $P R L$ prolactin

Another significant finding in this study was the direct association observed between LH and the central adiposity index (WHR) in both primary and secondary infertile women. Besides, no association was observed between any adiposity index and FSH levels in both primary and secondary infertile women. This findings deviates from previous report, which reported a positive association between central adiposity indices and FSH levels but not LH [10]. De Pergola et al. [21] also reported an inverse of adiposity indices with $\mathrm{LH}$ and FSH levels, which deviates from our present finding. In our findings, central adiposity indices (WC and WHtR) were positively correlated with LH levels among PCOS associated infertility. In line with a previous study [22] women with PCOS are most likely to have central fat distribution, which is associated with hyperandrogenaemia. Also, a neuroendocrine mark of PCOS is persistently rapid GnRH pulsatility, which favours pituitary synthesis of LH over that of FSH and contributes to the increased LH concentrations [23].

This study also observed a negative association between central adiposity indices (WC and WHtR) and prolactin levels in both primary and secondary infertile women. This finding is incongruent with a previous finding [10], which rather observed a positive association. The unique finding of this study was that prolactin levels of women with tubal factors as the cause of infertility showed negative association with central adiposity indices (WC and WHtR). Women with unexplained causes of infertility showed positive association between WC, WHtR and prolactin levels, which suggest possible obesity-induce hyperprolactinemia and poor fertility outcomes. Thus, we speculated that the association between central adiposity and prolactin levels is influenced by the underlying causes of infertility which merits future investigations.

Among hyperprolactinemia-associated infertility, a positive association was found between FSH levels and markers of central adiposity (WC and WHtR). Hyperprolactinemia affects $\mathrm{GnRH}$ neurons and pituitary gland function to reduce secretion of $\mathrm{LH}$ and $\mathrm{FSH}$, which represents an ovulatory disorder often associated with secondary amenorrhea or oligomenorrhea [24, 25]. Also, the interplay between fertility and obesity is the effect of obesity on menstrual disturbances $[9,10]$. Thus, we hypothesised an investigative associations of serum measures of ovarian reserve and ultrasound measurements of antral follicle counts with body size especially in hyperprolactinemia-associated infertility, which could better expound this observation.

Our findings suggest a direct association between adiposity indices and various hormonal derangements, which is largely dependent on the aetiology of infertility. Intervention undertaken to control central and visceral obesity would definitely provide a beneficial effect by correcting the hormonal imbalance. Therefore, we recommend that an effective weight-management intervention among infertile women is beneficial for their hormonal milieu, more appropriate for fertility. 
Table 3 Partial correlation of anthropometric measures with hormonal profile and aetiology of infertility as a fixed factor

\begin{tabular}{|c|c|c|c|c|c|c|c|c|c|c|}
\hline \multirow[t]{2}{*}{ Variables } & \multicolumn{5}{|c|}{ Polycystic ovarian syndrome } & \multicolumn{5}{|c|}{ Hyperprolactinemia } \\
\hline & PRG & FSH & LH & PRL & Ratio & PRG & FSH & LH & PRL & LH/FSH \\
\hline \multicolumn{11}{|l|}{ BMI } \\
\hline R & 0.15 & 0.09 & 0.08 & -0.07 & 0.14 & 0.11 & 0.40 & 0.33 & -0.35 & 0.22 \\
\hline$p$-value & 0.433 & 0.646 & 0.667 & 0.714 & 0.465 & 0.637 & 0.065 & 0.134 & 0.111 & 0.321 \\
\hline \multicolumn{11}{|l|}{ WC } \\
\hline R & 0.18 & 0.31 & 0.45 & -0.15 & -0.04 & 0.33 & 0.64 & 0.37 & -0.40 & 0.27 \\
\hline$p$-value & 0.335 & 0.100 & 0.012 & 0.436 & 0.822 & 0.133 & 0.001 & 0.089 & 0.067 & 0.222 \\
\hline \multicolumn{11}{|l|}{ WHR } \\
\hline R & -0.12 & 0.08 & 0.29 & -0.10 & 0.14 & -0.18 & 0.20 & 0.25 & -0.12 & 0.27 \\
\hline$p$-value & 0.532 & 0.659 & 0.118 & 0.598 & 0.446 & 0.432 & 0.376 & 0.270 & 0.605 & 0.225 \\
\hline \multicolumn{11}{|l|}{$\mathrm{WHtR}$} \\
\hline R & -0.01 & 0.22 & 0.38 & -0.06 & -0.07 & 0.26 & 0.58 & 0.32 & -0.38 & 0.22 \\
\hline$p$-value & 0.96 & 0.25 & 0.040 & 0.75 & 0.70 & 0.24 & 0.010 & 0.15 & 0.08 & 0.34 \\
\hline \multicolumn{11}{|l|}{ BAl } \\
\hline$R$ & -0.06 & 0.12 & 0.22 & -0.02 & -0.15 & 0.30 & 0.40 & 0.14 & -0.26 & 0.04 \\
\hline \multirow[t]{2}{*}{$p$-value } & 0.755 & 0.523 & 0.238 & 0.911 & 0.44 & 0.182 & 0.067 & 0.539 & 0.240 & 0.847 \\
\hline & \multicolumn{5}{|c|}{ Tubal cause } & \multicolumn{5}{|c|}{ Ovulation cause } \\
\hline \multicolumn{11}{|l|}{$\mathrm{BMI}$} \\
\hline R & 0.30 & -0.24 & -0.17 & -0.25 & -0.01 & 0.08 & 0.01 & 0.00 & -0.20 & 0.09 \\
\hline$p$-value & 0.068 & 0.160 & 0.327 & 0.130 & 0.957 & 0.731 & 0.951 & 0.985 & 0.372 & 0.692 \\
\hline \multicolumn{11}{|l|}{ WC } \\
\hline R & 0.27 & -0.35 & -0.08 & -0.53 & 0.31 & 0.13 & -0.05 & -0.02 & -0.33 & 0.15 \\
\hline$p$-value & 0.113 & 0.036 & 0.655 & 0.001 & 0.060 & 0.559 & 0.821 & 0.915 & 0.140 & 0.515 \\
\hline \multicolumn{11}{|l|}{ WHR } \\
\hline R & 0.40 & -0.12 & 0.10 & -0.41 & 0.28 & -0.33 & -0.25 & -0.13 & -0.03 & 0.33 \\
\hline$p$-value & 0.014 & 0.481 & 0.551 & 0.011 & 0.100 & 0.140 & 0.254 & 0.555 & 0.908 & 0.134 \\
\hline \multicolumn{11}{|l|}{$\mathrm{WHtR}$} \\
\hline R & 0.22 & -0.33 & -0.04 & -0.55 & 0.34 & 0.22 & -0.04 & -0.02 & -0.35 & 0.03 \\
\hline$p$-value & 0.193 & 0.049 & 0.814 & $<0.0001$ & 0.043 & 0.337 & 0.853 & 0.922 & 0.114 & 0.889 \\
\hline \multicolumn{11}{|l|}{$\mathrm{BAl}$} \\
\hline $\mathrm{R}$ & -0.10 & -0.35 & -0.13 & -0.44 & 0.23 & 0.53 & 0.25 & 0.19 & -0.41 & -0.23 \\
\hline \multirow[t]{2}{*}{$p$-value } & 0.541 & 0.033 & 0.445 & 0.006 & 0.173 & 0.011 & 0.268 & 0.402 & 0.057 & 0.312 \\
\hline & \multicolumn{5}{|c|}{ Male factor } & \multicolumn{5}{|c|}{ Unexplained cause } \\
\hline $\mathrm{BMI}$ & & & & & & & & & & \\
\hline R & -0.60 & 0.27 & -0.04 & -0.33 & -0.54 & -0.06 & -0.06 & 0.08 & 0.20 & 0.28 \\
\hline $\mathrm{p}$-value & 0.002 & 0.218 & 0.842 & 0.119 & 0.008 & 0.785 & 0.79 & 0.719 & 0.36 & 0.183 \\
\hline WC & & & & & & & & & & \\
\hline $\mathrm{R}$ & -0.54 & 0.27 & 0.35 & 0.08 & 0.23 & -0.06 & -0.26 & -0.09 & 0.48 & 0.35 \\
\hline$p$-value & 0.01 & 0.22 & 0.11 & 0.73 & 0.291 & 0.787 & 0.218 & 0.692 & 0.018 & 0.098 \\
\hline WHR & & & & & & & & & & \\
\hline $\mathrm{R}$ & -0.50 & 0.19 & 0.12 & -0.15 & 0.03 & -0.22 & 0.08 & 0.07 & 0.49 & 0.0 \\
\hline $\mathrm{p}$-value & 0.02 & 0.40 & 0.59 & 0.505 & 0.878 & 0.307 & 0.72 & 0.743 & 0.014 & 0.986 \\
\hline $\mathrm{WH} \mathrm{tR}$ & & & & & & & & & & \\
\hline $\mathrm{R}$ & -0.56 & 0.15 & 0.16 & 0.02 & 0.05 & -0.13 & -0.29 & -0.15 & 0.49 & 0.24 \\
\hline $\mathrm{p}$-value & 0.010 & 0.500 & 0.480 & 0.927 & 0.834 & 0.533 & 0.171 & 0.484 & 0.016 & 0.254 \\
\hline $\mathrm{BAl}$ & & & & & & & & & & \\
\hline$R$ & -0.21 & -0.04 & -0.06 & 0.05 & -0.13 & -0.04 & -0.47 & -0.31 & 0.20 & 0.26 \\
\hline$p$-value & 0.330 & 0.867 & 0.772 & 0.813 & 0.554 & 0.872 & 0.02 & 0.142 & 0.347 & 0.219 \\
\hline
\end{tabular}

Values highlighted in italics are statistically significant

$R$ partial correlation coefficient (adjusted for primary and secondary infertility), BMI body mass index, WC waist circumference, $W H R$ waist-to-hip ratio, WHtR waist-toheight ratio, $B A /$ body adiposity index, $P R G$ progesterone, $F S H$ follicle stimulating hormone, $L H$ luteinizing hormone, $P R L$ prolactin 


\section{Limitations}

The lack of a control population or available anthropometric national data to compare our results is a major limitations of our study. Also, the measurements of thyroid stimulating hormones, glucose and lipids as well as oestrogen and testosterone would have been beneficial to clearly explain some of the findings between obesity and hormone levels, which is a limitation to this study.

\section{Abbreviations}

FSH: follicle stimulating hormone; LH: luteinizing hormone; PRL: prolactin; GnRH: gonadotropin releasing hormone; PCOS: polycystic ovarian syndrome; BMI: body mass index; WC: waist circumference; WHR: waist-to-hip ratio; WHtR: waist-to-height ratio; BAl: body adiposity index.

\section{Acknowledgements}

The Authors acknowledge the hard work of the Staff of the Departments of Obstetrics and Gynaecology of the Komfo Anokye Teaching Hospital, in their substantial contribution to the success of this study. We also acknowledge the Principal Investigator and his colleagues at the Department of Molecular Medicine, School of Medical Sciences, Kwame Nkrumah University of Science and Technology for their inputs on the design and accomplishment of the study.

\section{Authors' contributions}

WKBAO, PNO, CAT and CO were involved in conceptualization, methodology, supervision, validation, writing - review and editing. EA, EOA and EWO were involved in data curation, investigation, methodology, writing - original draft, writing - review and editing, EAA was involved in conceptualization, methodology, validation, formal analysis, writing-original draft and writing-review and editing. All authors read and approved the final manuscript.

\section{Funding}

No funding was obtained for the study.

\section{Availability of data and materials}

The datasets used and analyzed during the study are available from the corresponding author on reasonable request.

\section{Ethics approval and consent to participate}

The study was approved by the Committee on Human Research, Publications and Ethics (CHRPE), School of Medical Sciences, Kwame Nkrumah University of Science \& Technology (KNUST), Kumasi and the Komfo Anokye Teaching Hospital (KATH) ethical committee board. All patients enrolling in the study completed a written informed consent form in accordance with the Helsinki Declaration.

\section{Consent for publication}

Not applicable.

\section{Competing interests}

The authors declare that they have no competing interests.

\section{Author details}

${ }^{1}$ Department of Molecular Medicine, School of Medicine and Dentistry, Kwame Nkrumah University of Science and Technology, Kumasi, Ghana. ${ }^{2}$ Independent Development Research Consultant, Total Family Health Organization, Accra, Ghana. ${ }^{3}$ Department of Obstetrics and Gynaecology, Komfo Anokye Teaching Hospital, Kumasi, Ghana. ${ }^{4}$ School of Medical and Health Sciences, Edith Cowan University, Joondalup, WA, Australia.

Received: 21 July 2019 Accepted: 22 August 2019

Published online: 28 August 2019

\section{References}

1. Boivin J, Bunting L, Collins JA, Nygren KG. International estimates of infertility prevalence and treatment-seeking: potential need and demand for infertility medical care. Hum Reprod. 2007;22(6):1506-12.

2. Inhorn MC. Global infertility and the globalization of new reproductive technologies: illustrations from Egypt. Soc Sci Med. 2003;56(9):1837-51.

3. Ombelet W. Global access to infertility care in developing countries: a case of human rights, equity and social justice. Facts Views Vis ObGyn. 2011;3(4):257.

4. Nachtigall RD. International disparities in access to infertility services. Fertil Steril. 2006;85(4):871-5.

5. Mascarenhas MN, Flaxman SR, Boerma T, Vanderpoel S, Stevens GA. National, regional, and global trends in infertility prevalence since 1990: a systematic analysis of 277 health surveys. PLoS Med. 2012;9(12):e1001356.

6. Geelhoed D, Nayembil D, Asare K, Schagen van Leeuwen JH, Van Roosmalen J. Infertility in rural Ghana. Int J Gynecol Obstet. 2002;79(2):137-42.

7. Cetin I, Cozzi V, Antonazzo P. Infertility as a cancer risk factor-a review. Placenta. 2008;29:169-77.

8. Chang RJ. The reproductive phenotype in polycystic ovary syndrome. Nat Rev Endocrinol. 2007;3(10):688.

9. Pandey S, Pandey S, Maheshwari A, Bhattacharya S. The impact of female obesity on the outcome of fertility treatment. J Hum Reprod Sci. 2010;3(2):62.

10. Seth B, Arora S, Singh R. Association of obesity with hormonal imbalance in infertility: a cross-sectional study in north Indian women. Indian J Clin Biochem. 2013;28(4):342-7.

11. Wintermantel TM, Campbell RE, Porteous R, Bock D, Gröne H-J, Todman MG, Korach KS, Greiner E, Pérez CA, Schütz G. Definition of estrogen receptor pathway critical for estrogen positive feedback to gonadotropin-releasing hormone neurons and fertility. Neuron. 2006;52(2):271-80.

12. Conn PD, Michael P, Crowley M Jr, William F. Gonadotropin-releasing hormone and its analogs. Ann Rev Med. 1994;45(1):391-405.

13. Cramer D, Sluss P, Powers R, McShane P, Ginsburg E, Hornstein M, Vitonis A, Barbieri R. Serum prolactin and TSH in an in vitro fertilization population: is there a link between fertilization and thyroid function? J Assist Reprod Genet. 2003;20(6):210-5.

14. Brandebourg T, Hugo E, Ben-Jonathan N. Adipocyte prolactin: regulation of release and putative functions. Diabetes Obes Metab. 2007;9(4):464-76

15. Guerrero-Romero F, Rodríguez-Morán M. Abdominal volume index. An anthropometry-based index for estimation of obesity is strongly related to impaired glucose tolerance and type 2 diabetes mellitus. Arch Med Res. 2003;34(5):428-32.

16. Freedman DS, Thornton JC, Pi-Sunyer FX, Heymsfield SB, Wang J, Pierson RN Jr, Blanck HM, Gallagher D. The body adiposity index (hip circumference $\div$ height 1.5$)$ is not a more accurate measure of adiposity than is BMI, waist circumference, or hip circumference. Obesity. 2012;20(12):2438-44

17. Dunson DB, Baird DD, Colombo B. Increased infertility with age in men and women. Obstet Gynecol. 2004;103(1):51-6.

18. Broekmans F, Kwee J, Hendriks D, Mol B, Lambalk C. A systematic review of tests predicting ovarian reserve and IVF outcome. Hum Reprod Update. 2006;12(6):685-718.

19. Al-Turki HA. Prevalence of primary and secondary infertility from tertiary center in eastern Saudi Arabia. Middle East Fertil Soci J. 2015;20(4):237-40.

20. Scott RT Jr, Elkind-Hirsch KE, Styne-Gross A, Miller KA, Frattarelli JL. The predictive value for in vitro fertility delivery rates is greatly impacted by the method used to select the threshold between normal and elevated basal follicle-stimulating hormone. Fertil Steril. 2008;89(4):868-78.

21. De Pergola G, Maldera S, Tartagni M, Pannacciulli N, Loverro G, Giorgino R. Inhibitory effect of obesity on gonadotropin, estradiol, and inhibin B levels in fertile women. Obesity. 2006;14(11):1954-60.

22. Diamanti-Kandarakis E. Role of obesity and adiposity in polycystic ovary syndrome. Int J Obes. 2007;31(S2):S8.

23. Blank S, McCartney C, Marshall J. The origins and sequelae of abnormal neuroendocrine function in polycystic ovary syndrome. Hum Reprod Update. 2006;12(4):351-61. 
24. Majumdar A, Mangal NS. Hyperprolactinemia. J Hum Reprod Sci. 2013;6(3):168-75.

25. Kaiser UB. Hyperprolactinemia and infertility: new insights. J Clin Investig. 2012;122(10):3467-8.

\section{Publisher's Note}

Springer Nature remains neutral with regard to jurisdictional claims in published maps and institutional affiliations.
Ready to submit your research? Choose BMC and benefit from:

- fast, convenient online submission

- thorough peer review by experienced researchers in your field

- rapid publication on acceptance

- support for research data, including large and complex data types

- gold Open Access which fosters wider collaboration and increased citations

- maximum visibility for your research: over 100M website views per year

At BMC, research is always in progress.

Learn more biomedcentral.com/submissions 